\title{
Characterizing User Behaviours and Products in an Online Educational Community: A Comparison between Novices and Elders
}

\author{
Min Yuan and Mimi Recker \\ Utah State University \\ mimi.recker@usu.edu
}

\begin{abstract}
This study focuses on two user types in an online educational community - novices and elders - and explores the characteristics of their behaviours and contributed products by analyzing usage logs. Results show that novices and elders have different behavioural trajectories. In addition, the products created by elders attract more views.
\end{abstract}

KEYWORDS: Online educational community, novices, user behaviours

\section{INTRODUCTION}

Many online educational communities (OECs), such as the Instructional Architect and Tapped In, have been established to facilitate user knowledge building, promote mutual interaction, and meet educational needs (Preece \& Maloney-Krichmar, 2003; Recker, 2006; Suthers \& Dwyer, 2014). By examining time spent in an OEC and the levels of participation, different user types can be identified. For example, we define novices as new members of an OEC, and elders as users who have participated in an OEC for some time and make frequent contributions (Bishop, 2007). Investigating the differences between novices and elders is important, as it allows researchers to understand the evolution of user behaviours and characteristics of the products they contribute (e.g., discussions, comments, educational artifacts). It also offers implications on the sustainability of OECs.

The purpose of this study is to identify the differences between novices and elders based on the usage logs from a free, web-based tool called the Instructional Architect (IA.usu.edu). The IA allows teachers to build shared repositories of educational content and support each other. Teachers can contribute to repositories by creating new products, modifying existing products, and adding external resources to their products (Recker, 2006). They can support each other by publishing their products, so other users can view and even copy their products. In particular, this study compares the behaviours and resulting products between 386 novices who created accounts in the IA during 2013 and 152 elders who created accounts before 2013 and actively participated during 2013.

\section{THEORETICAL CONTEXT}

The rapid growth in Internet technologies has given rise to many OECs, which provide features to meet 
(2014). Characterizing User Behaviours and Products in an Online Educational Community: A Comparison between Novices and Elders. Journal of Learning Analytics, 1(3), 150-153.

teachers' instructional needs (Andrews, Preece, \& Turoff, 2001). The way users use features of an OEC varies. For example, some prefer to create products using their own knowledge, some tend to build on and remix external resources in their products, while others may simply view other users' products (Yuan \& Recker, 2014). In addition, user behaviours in an OEC are dynamic across time. For example, novices may be initially attracted to an OEC, and some eventually become key contributors and elders, while others leave after a short time (Iriberri \& Leroy, 2009). In this way, the dynamics of user behaviours can affect the sustainability of the whole community.

Further, Farzan, DiMicco, \& Brownholtz (2009) noted that users' products can affect the sustainability of an OEC, as these products can help attract new users and influence existing users to remain in the community. Thus, describing user behaviours and characterizing users' products can lead to a better understanding of the sustainability of an OEC. However, little research has focused on both aspects, especially drawing upon the usage logs of a specific community. In response, this study compared behaviours and products between novices and elders, and concludes with suggestions on how to improve the sustainability of OECs.

\section{METHOD}

This study addresses two questions oriented towards the IA community: 1) How did novices differ from elders in terms of their behaviours in 2013? 2) How did novices differ from elders in terms of the products each group created during 2013? We collected data from the IA database and analyzed it using descriptive statistics. We also used the Mann-Whitney test due to non-normal distribution.

\section{RESULTS}

\subsection{A Comparison of User Behaviours}

First, on average, novices created more products, but made fewer modifications and incorporated fewer external resources than elders (see Table 1). However, the Mann-Whitney test reveals that these differences are not significant. Second, novices and elders show different behavioural trajectories. In general, novices exhibited high activities after creating their accounts, after which their activities decreased. For example, novices created almost $50 \%$ of their products during the month they joined the community. On the contrary, elders made steady contributions to the IA throughout 2013.

Table 1: Comparison of behaviours between novices and elders.

\begin{tabular}{l|r|c|c|c|c|c}
\hline \multirow{2}{*}{ Metrics } & \multicolumn{3}{c|}{ Novices (N=386) } & \multicolumn{3}{c}{ Elders (N=152) } \\
\cline { 2 - 7 } & Mean & Median & SD & Mean & Median & SD \\
\hline \# of products created & 1.32 & 0 & 2.50 & 1.16 & 0 & 2.43 \\
\hline \# of modifications of products & 22.38 & 0 & 45.37 & 23.51 & 0 & 53.75 \\
\hline \# of external resources added to products & 3.62 & 0 & 11.08 & 5.65 & 0 & 14.60 \\
\hline
\end{tabular}


(2014). Characterizing User Behaviours and Products in an Online Educational Community: A Comparison between Novices and Elders. Journal of Learning Analytics, 1(3), 150-153.

\subsection{A Comparison of Resulting Products}

During 2013, novices created 510 products and elders created 177 products, but elders' products were viewed significantly more times $(U=31637.50, p<.01$; see Table 2$)$. This suggests that elders contributed products that are more beneficial to users.

Table 2: Comparison of products between novices and elders.

\begin{tabular}{l|c|c|c|c|c|c}
\hline \multirow{2}{*}{ Metrics } & \multicolumn{2}{|c|}{ Novices' products (N=510) } & \multicolumn{3}{c}{ Elders' products (N=177) } \\
\cline { 2 - 7 } & Mean & Median & SD & Mean & Median & SD \\
\hline \# of times products being viewed* & 12.41 & 3 & 43.25 & 133.32 & 17 & 388.04 \\
\hline \# of times products being copied & .01 & 0 & .11 & .03 & 0 & .20 \\
\hline
\end{tabular}

\section{CONCLUSION}

This study offers a series of suggestions on improving the sustainability of OECs, such as providing support and dissemination to retain novice interest, especially within the first few months after they join the community, and highlighting elders' products to attract more new users. Furthermore, this study contributes to learning analytics, as it offers examples of how to trace and compare user behaviour and users' products based on usage logs (Ferguson \& Buckingham Shum, 2012). This work is part of an ongoing series of studies; a forthcoming study uses logistic regression to investigate which variable(s) predict whether novices remain in the IA community.

\section{REFERENCES}

Andrews, D., Preece, J., \& Turoff, M. (2001). A conceptual framework for demographic groups resistant to online community interaction. International Journal of Electronic Commerce, 6(3), 9-24.

Bishop, J. (2007). Increasing participation in online communities: A framework for human-computer interaction. Computers in human behavior, 23(4), 1881-1893.

Farzan, R., DiMicco, J. M., \& Brownholtz, B. (2009, May). Spreading the honey: A system for maintaining an online community. Proceedings of the ACM 2009 International Conference on Supporting Group Work (pp. 31-40). New York: ACM.

Ferguson, R., \& Buckingham Shum, S. (2012, April). Social learning analytics: Five approaches. Proceedings of the 2nd International Conference on Learning Analytics and Knowledge (pp. 2333). New York: ACM.

Iriberri, A., \& Leroy, G. (2009). A life-cycle perspective on online community success. ACM Computing Surveys (CSUR), 41(2), 11.

Preece, J., \& Maloney-Krichmar, D. (2003) Online Communities. In J. Jacko and A. Sears (Eds.) Handbook of human-computer interaction. Mahwah, NJ: Lawrence Erlbaum Associates, 596-620.

Recker, M. (2006). Perspectives on teachers as digital library users: Consumers, contributors, and 


\section{JOURNAL OF LEARNING ANALYTICS}

(2014). Characterizing User Behaviours and Products in an Online Educational Community: A Comparison between Novices and Elders. Journal of Learning Analytics, 1(3), 150-153.

designers. D-Lib Magazine, 12(9), 2.

Suthers, D., \& Dwyer, N. (2014). Multilevel analysis of uptake, sessions, and key actors in a sociotechnical network. In Computational Approaches to Connecting Levels of Analysis in Networked Learning Communities, a Workshop at Learning Analytics and Knowledge 2014, 24-28 March 2014, Indianapolis, IN.

Yuan, M., \& Recker, M. (2014). Dissemination matters: Influences of dissemination activities on user types in an online educational community. International Journal of Artificial Intelligence and Interactive Multimedia, 2(7), 22-29. 